\title{
Pups Call, Mothers Rush: Does Maternal Responsiveness Affect the Amount of Ultrasonic Vocalizations in Mouse Pups?
}

Francesca R. D'Amato · Elisabetta Scalera •

Celeste Sarli · Anna Moles

Published online: 5 May 2006

(C) Springer Science+Business Media, Inc. 2006

Behavior Genetics 35(1), 103-112

DOI 10.1007/s10519-004-0860-9

In the paper " Pups Call, Mothers Rush: Does Maternal Responsiveness affect the Amount of Ultrasonic Vocalizations in Mouse Pups?' Figure 1 was incorrect.

The black bars referred to BALB/C while the white bars to C57BL/6 mice. The correct figure is published below. The authors apologize for any confusion caused.

The online version of the original article can be found at http:// dx.doi.org/10.1007/s10519-004-0860-9

F. R. D’Amato $(\square) \cdot$ E. Scalera ·

Celeste Sarli $\cdot$ A. Moles

Psychobiology and Psychopharmacology,

CNR Institute of Neuroscience, Viale Marx 43,

00137 Roma, Italy

e-mail: f.damato@ipsifar.rm.cnr.it

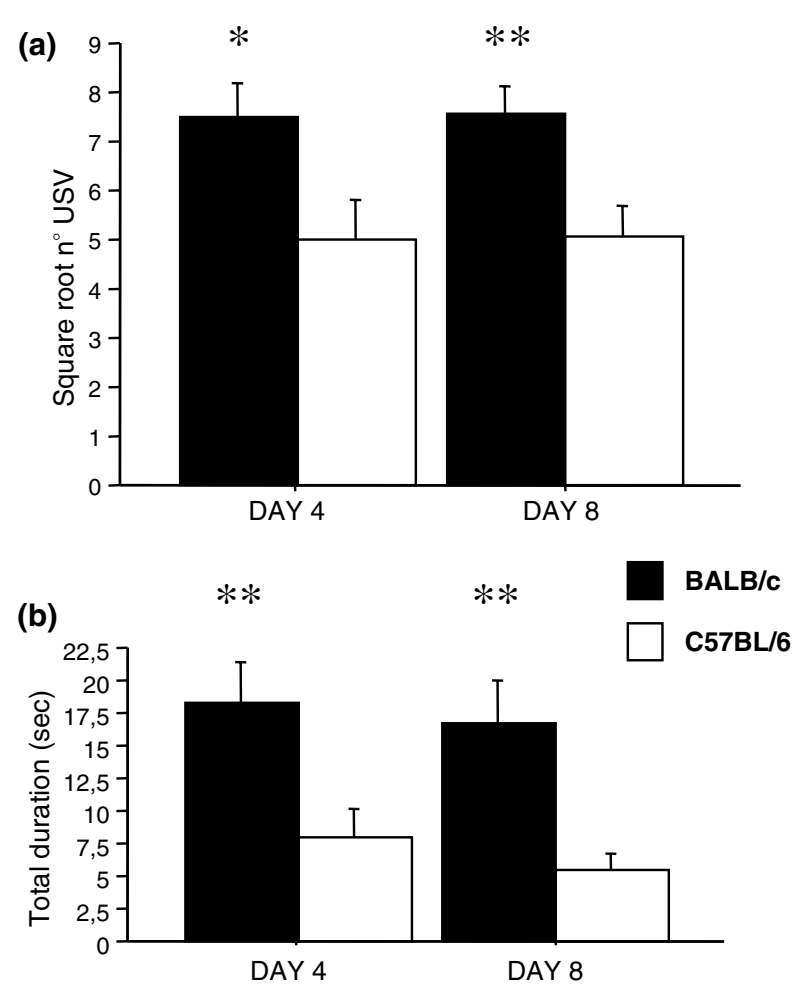

Fig. 1 Square root transformed number (a) and total duration (b) of ultrasonic calls emitted by 4- and 8-day-old C57BL/6 (white bars) $\mathrm{BALB} / \mathrm{C}$ (black bars) pups during $5 \mathrm{~min}$ of isolation at room temperature. Data are mean + SE. $* p<0.05 ; * * p<0.01$ Tukey HSD versus $\mathrm{BALB} / \mathrm{c}$ 